Original Research Article

\title{
A prospective study to assess the prevalence of hepatitis $B$ infection in health care workers, voluntary blood donors, and patients with liver disorders at a tertiary care centre
}

\author{
Purshottam K. Kaundal $^{1 *}$, Anju Partap Kaundal ${ }^{2}$
}

\begin{abstract}
${ }^{1}$ Department of Pharmacology, ${ }^{2}$ Department of Anatomy, Dr. Yaswant Singh Parmar, Govt. Medical College, Nahan, Himachal Pradesh, India
\end{abstract}

Received: 25 April 2017 Accepted: 24 May 2017

\section{*Correspondence to:}

Dr. Purshottam K. Kaundal, Email: indi4787@gmail.com

Copyright: (C) the author(s), publisher and licensee Medip Academy. This is an openaccess article distributed under the terms of the Creative Commons Attribution NonCommercial License, which permits unrestricted noncommercial use, distribution, and reproduction in any medium, provided the original work is properly cited.

\begin{abstract}
Background: Hepatitis B virus (HBV) is highly infectious when compared with human immuno-deficiency virus (HIV), even minute quantity of infected blood as little as $0.0001 \mathrm{ml}$ can transmit infection. A number of the routine therapeutic, diagnostic, prophylactic invasive procedures can spread HBV infection. The study was planned to assess the prevalence of hepatitis B surface antigen in health care workers, voluntary blood donors, and patients with liver disorders.

Methods: The study was a cross sectional study carried out among 90 subjects during a period of one year in Indira Gandhi Medical College and Hospital, Shimla. These 90 subjects consisted of 30 patients with liver disorder, 30 health care workers and 30 voluntary blood donors. The blood samples were collected and sent for detection of HBsAg by ELISA.

Results: Majority of the subjects $47(52.2 \%)$ belonged to the age group of 2130 years. Among voluntary blood donors, $90 \%$ were males. $64.4 \%$ of the subjects belonged to urban areas. $50 \%$ of the rural subjects were having liver disorders. Liver disorder was more common (71.5\%) among heterosexual high risk behaviour subjects compared to only $25.7 \%$ with no high risk behaviour. Seropositivity was found highest among patients with liver disorder $(66.7 \%)$ followed by health care workers (20\%). Overall, the seropositivity was $28.9 \%$.

Conclusions: Patients with liver disorders especially chronic hepatitis were mostly seropositive. Among health care workers, being a doctor was a significant risk factor for acquiring hepatitis B infection. Thus, it is advised that all health care workers should be immunized for hepatitis B.
\end{abstract}

Keywords: Hepatitis B, Health care workers, Liver disorders, Seropositivity

\section{INTRODUCTION}

Hepatitis B viral infection is prevalent worldwide. Natural infection occurs only in humans and there are no animal reservoirs for hepatitis B virus (HBV). HBV is a blood borne virus and infection is transmitted by parenteral, perinatal, sexual, and other modes of transmission. The virus also shows its presence in all body fluids and excretions due to its infection such as tears, breast milk, vaginal secretions, semen, urine, bile, and faces etc. which can also transmit the infection to healthy individuals. The virus is sustained in a large pool of carriers whose blood contains circulating virus for a long period. There are over 450 million carriers worldwide and among them around 45 million are in India, the second largest carrier pool next to China in the world. ${ }^{1}$

Transmission through infected blood is one of the most common modes of transmitting the HBV infection, so entails strict screening for safe blood transfusion. Sexual transmission of HBV occurs in commercial sex workers, homosexuals and those who involve in high risk behaviour i.e. heterosexuals. ${ }^{2}$ Certain occupational groups bears higher risk of $\mathrm{HBV}$ infection including medical and paramedical personnel in the hospital, in the areas like blood bank, dialysis unit etc. ${ }^{3}$ 
The presence of hepatitis B surface antigen HBsAg in association with hepatitis and its prolonged course leads to high incidence of complications like cirrhosis of liver, chronic active hepatitis and hepatocellular carcinoma. The lengthy course and prevalence of HBV among the community results in the horizontal spread and thereby leads to high morbidity and mortality. ${ }^{4} \mathrm{HBV}$ is highly infectious when compared with HIV; even tiny traces of infected blood as little as $0.0001 \mathrm{ml}$ can transmit infection. Many of the routine therapeutic, diagnostic, and prophylactic invasive procedures are capable of spreading HBV infection. ${ }^{5}$

So, this study was planned to know the prevalence of hepatitis B surface antigen in health care workers (medical and paramedical personnel), voluntary blood donors, and patients with liver disorders at a tertiary care centre.

\section{METHODS}

\section{Study design and set up}

The study was conducted at Indira Gandhi Medical College and Hospital Shimla, Himachal Pradesh which is also a tertiary care centre of the state; it covers the majority of the population of the state. The study was conducted over a period from July 2015 to June 2016. It was a prospective cross-sectional study. The study protocol was approved by Indira Gandhi Medical College ethical committee, Shimla, Himachal Pradesh. A total of 90 subjects were enrolled, consisting of 30 health care workers, 30 patients with liver disorder, and 30 voluntary blood donors. All of these were selected randomly. After obtaining written informed consent, detailed history and examination was carried out. The blood samples were collected and sent for detection of HBsAg by ELISA.

\section{Inclusion criteria}

- Health care workers and voluntary blood donors free from any disease.

- Patients with liver disorder confirmed by the treating physician.

- Willingness to participate in the study.

\section{Exclusion criteria}

- Unstable patients or those suffering from severe debilitating illness.

- Subjects not willing to participate in the study.

\section{Sample collection}

Blood samples were collected for serological diagnosis of HBV infection by following aseptic methods i.e. disinfecting the site collection of blood sample by venipuncture method. 3-5 ml of blood sample was collected with $5 \mathrm{ml}$ syringe and transferred to sterile test tubes. The collected blood samples were sent to the department of microbiology. These samples were then allowed to clot for 30 minutes and centrifuged at $3000 \mathrm{rpm}$ for 15 minutes to allow for the segregation of the serum for each sample.

The separated sera were then transferred into sterile Laxbro vials and were kept at 2-8 degree Celsius in the refrigerator. All the 90 samples were tested by ELISA method for HBsAg detection in the sera using SD HBsAg ELISA SD 3.0 BIOLINE diagnostic kit.

\section{Re-constitution of reagents in the test kit}

The test kit which was utilized for the detection of HBsAg was the SD HBsAg ELISA SD 3.0 BIOLINE. This kit was kept in sterile conditions at 2-8 degree Celsius as guided by the kit literature. The kit was brought to room temperature before conducting the test. The required articles like micropipette, glass ware for preparing reagents etc. were brought to the place where the test was to be performed.

Materials in the kit and method for composing the reagent kit:

- Coated micro-plates: 96 well coated with antihepatitis B surface antigen (anti-HBS) were kept at 2-8 degree Celsius in the provided aluminium bag and precisely sealed.

- Enzyme conjugate: Anti-HBS conjugated to horseradish peroxide (HRPO), the preservative used was proclin (300qs) which was ready to use.

- Positive control: HBsAg positive human serum [the preservative used was proclin (300 qs)].

- $\quad$ Negative control: Normal healthy human serum [the preservative used was proclin (300 qs)].

- Substrate: Tetramethyl benzidine with citrate phosphate buffer and DMSO 101X concentrated was provided which were diluted in a sterile glass ware just before use. Making 1:100 mixtures with substrate concentrate and substrate diluents.

- Substrate diluents: Citrate-phosphate buffer and hydrogen peroxide.

- Washing solution: PBS TWEEN 20, 20 X concentrations was provided. $25 \mathrm{ml}$ of was concentrate was taken and filed up to $500 \mathrm{ml}$ with distilled water in the washing tank.

- Stop solution: 1.6 N sulphuric acids which were ready to use was provided.

\section{Statistical analysis}

In the study, various variables were compared using appropriate statistical methods. Data was entered in Microsoft Excel and analysed using proportions and the appropriate statistical tools. 


\section{RESULTS}

In the present study majority of the patients $47(52.2 \%)$ belonged to the age group of 21-30 years overall, as well as among the voluntary blood donors i.e. $60 \%$. Among voluntary blood donors, $90 \%$ were males. $64.4 \%$ belonged to urban areas. Among rural subjects, majority of the patients $(50 \%)$ were having liver disorders. Only $23.3 \%$ were illiterate. Liver disorder was more common among illiterates $(82.3 \%)$. Overall only $22.2 \%$ were having high risk behaviour and all of them were heterosexuals. $77.8 \%$ were not having any high risk behaviour. Liver disorder was more common (75\%) among heterosexual high risk behaviour subjects compared to only $25.7 \%$ with no high risk behaviour.

Maximum (38.5\%) seropositivity was found among doctors followed by nurses $(16.7 \%)$. None of the subjects was found seropositive among dentists, lab technicians and housekeeping staff. None were positive among patients with cirrhosis of liver but the seropositivity was $74.1 \%$ among patients with chronic hepatitis. Seropositivity was found highest among patients with liver disorder $(66.7 \%)$ followed by health care workers $(20 \%)$. None of the patients was seropositive among voluntary blood donors. Overall the seropositivity was $28.9 \%$.

Table 1: Age and sex distribution of study subjects.

\begin{tabular}{|c|c|c|c|c|c|c|c|}
\hline \multirow{2}{*}{$\begin{array}{l}\text { Age group } \\
\text { (years) }\end{array}$} & \multicolumn{2}{|c|}{ Voluntary blood donors } & \multicolumn{2}{|c|}{ Patients with liver disorders } & \multicolumn{2}{|c|}{ Health care workers } & \multirow{2}{*}{ Total } \\
\hline & Male & Female & Male & Female & Male & Female & \\
\hline$<20$ & $01(3.3 \%)$ & 0 & $02(6.7 \%)$ & $01(3.3 \%)$ & 0 & 0 & $04(4.4 \%)$ \\
\hline $21-30$ & $18(60 \%)$ & 0 & $07(23.3 \%)$ & $04(13.3 \%)$ & $10(33.3 \%)$ & $08(26.7 \%)$ & $47(52.2 \%)$ \\
\hline $31-40$ & $06(20 \%)$ & $03(10 \%)$ & $02(6.7 \%)$ & $02(6.7 \%)$ & $02(6.7 \%)$ & $03(10 \%)$ & $18(20 \%)$ \\
\hline $41-50$ & $02(6.7 \%)$ & 0 & $01(3.3 \%)$ & $03(10 \%)$ & $02(6.7 \%)$ & $03(10 \%)$ & $11(12.2 \%)$ \\
\hline $51-60$ & 0 & 0 & $03(10 \%)$ & $02(6.7 \%)$ & $01(3.3 \%)$ & $01(3.3 \%)$ & $07(7.9 \%)$ \\
\hline $61-70$ & 0 & 0 & $02(6.7 \%)$ & 0 & 0 & 0 & $02(2.2 \%)$ \\
\hline $71-80$ & 0 & 0 & $01(3.3 \%)$ & 0 & 0 & 0 & $01(1.1 \%)$ \\
\hline Total & $27(90 \%)$ & $03(10 \%)$ & $18(60 \%)$ & $12(40 \%)$ & $15(50 \%)$ & $15(50 \%)$ & $90(100 \%)$ \\
\hline
\end{tabular}

Table 2: Distribution of study subjects as per various demographic data.

\begin{tabular}{|c|c|c|c|c|c|}
\hline \multicolumn{2}{|c|}{ Demographic factors } & $\begin{array}{l}\text { Voluntary blood } \\
\text { donors }\end{array}$ & $\begin{array}{l}\text { Patients with } \\
\text { liver disorders }\end{array}$ & $\begin{array}{l}\text { Health care } \\
\text { workers }\end{array}$ & Total \\
\hline \multirow{2}{*}{ Locality } & Rural & $10(31.3 \%)$ & $16(50 \%)$ & $06(18.7 \%)$ & $32(35.6 \%)$ \\
\hline & Urban & $16(27.6 \%)$ & $20(34.5 \%)$ & $22(37.9 \%)$ & $58(64.4 \%)$ \\
\hline \multirow{3}{*}{ Literacy } & Illiterate & $05(17.6 \%)$ & $16(82.3 \%)$ & 0 & $21(23.3 \%)$ \\
\hline & Primary education & $05(20 \%)$ & $19(76 \%)$ & $01(4 \%)$ & $25(27.7 \%)$ \\
\hline & Secondary education and higher & $07(15.9 \%)$ & $05(11.4 \%)$ & $32(72.7 \%)$ & $44(48.9 \%)$ \\
\hline \multirow{3}{*}{$\begin{array}{l}\text { High risk } \\
\text { behaviour }\end{array}$} & Homosexual & 0 & 0 & 0 & 0 \\
\hline & Heterosexual & $04(20 \%)$ & $15(75 \%)$ & $01(5 \%)$ & $20(22.2 \%)$ \\
\hline & No high risk behaviour & $20(28.6 \%)$ & $18(25.7 \%)$ & $52(74.3 \%)$ & $70(77.8 \%)$ \\
\hline
\end{tabular}

Table 3: Seropositivity among voluntary blood donors.

\begin{tabular}{|lllllll|}
\hline Sex & Seropositive & & Seronegative & & Total \\
& Number & Percentage & Number & Percentage & Number & Percentage \\
\hline Male & 0 & 0 & 29 & 100 & 29 & 96.7 \\
\hline Female & 0 & 0 & 01 & 100 & 01 & 3.3 \\
\hline
\end{tabular}

Table 4: Seropositivity among health care workers.

\begin{tabular}{|lllllll|}
\hline & Seropositive & & Seronegative & \multicolumn{2}{c|}{ Total } \\
& Number & Percentage & Number & Percentage & Number & Percentage \\
\hline Doctors & 05 & 38.5 & 08 & 61.5 & 13 & 43.3 \\
\hline Dentists & 0 & 0 & 01 & 100 & 01 & 3.3 \\
\hline Nurses & 01 & 16.7 & 05 & 83.3 & 06 & 20 \\
\hline Lab technicians & 0 & 0 & 07 & 100 & 07 & 23.3 \\
\hline Housekeeping staff & 0 & 0 & 03 & 100 & 03 & 10 \\
\hline Total & 06 & 20 & 24 & 80 & 30 & 100 \\
\hline
\end{tabular}


Table 5: Seropositivity among patients with liver disorders.

\begin{tabular}{|lllllll|}
\hline \multirow{2}{*}{ Liver disorder } & Seropositive & \multicolumn{3}{c}{ Seronegative } & Total & Percentage \\
\hline & Number & Percentage & Number & Percentage & Number & 90 \\
\hline Chronic hepatitis & 20 & 74.1 & 07 & 25.9 & 27 & 10 \\
\hline Cirrhosis of liver & 0 & 0 & 03 & 100 & 03 & 03 \\
\hline
\end{tabular}

Table 6: Comparison of seropositivity among three groups.

\begin{tabular}{|lllllll|l|}
\hline \multirow{2}{*}{ Groups } & Seropositive & \multicolumn{2}{l|}{ Seronegative } & \multicolumn{2}{l|}{ Total } \\
\cline { 2 - 7 } & Number & Percentage & Number & Percentage & Number & Percentage \\
\hline Voluntary blood donors & 00 & 00 & 30 & 100 & 30 & 33.3 \\
\hline Health care workers & 06 & 20 & 24 & 80 & 30 & 33.3 \\
\hline Patients with liver disorder & 20 & 66.7 & 10 & 33.3 & 30 & 33.3 \\
\hline Total & 26 & 28.9 & 64 & 71.1 & 90 & 100 \\
\hline
\end{tabular}

\section{DISCUSSION}

In our study, most of the patients $(52.2 \%)$ belonged to the age group of 21-30 years overall, and among the voluntary blood donors $(60 \%)$ followed by $20 \%$ in the age group of $31-40$ years. Among voluntary blood donors, $90 \%$ were males. $64.4 \%$ of the total subjects belonged to urban areas. Among rural subjects, majority of the patients $(50 \%)$ were having liver disorders. Only $23.3 \%$ were illiterate in the entire study group. Liver disorder was more common among illiterates (82.3\%) followed by $76 \%$ in patients who were educated till primary level. On the whole, only $22.2 \%$ were having high risk behaviour and all of them were heterosexuals. $77.8 \%$ did not show any high risk behaviour. In our study, none of the subjects was homosexual.

Highest $(38.5 \%)$ seropositivity was seen among doctors followed by nurses (16.7\%). No one was found seropositive among dentists, lab technicians and housekeeping staff. None of the patients with cirrhosis of liver was found to be seropositive. However, the seropositivity was $74.1 \%$ among patients with chronic hepatitis. Seropositivity was recorded highest among patients with liver disorder $(66.7 \%)$ followed by health care workers $(20 \%)$. None of the patients was seropositive among voluntary blood donors. Overall the seropositivity was $28.9 \%$. Gupta $\mathrm{N}$ et al noted a positivity rate of $0.66 \%$ among 44064 voluntary blood donors screened by them. ${ }^{6,7}$ Patel $\mathrm{Y}$ et al, found a seroprevalence of $1.7 \%$ among voluntary blood donors. Elavia AJ et al reported a $10 \%$ seroprevalence among health care workers which is similar to that reported in our study $(20 \%){ }^{5}$ Present study observed a seroprevalence of $66.7 \%$ among patients with liver disorder which is incoherence to that found by Vaiphei K et al (70\%). ${ }^{8}$

Shivananda PG et al, conducted a study among voluntary blood donors, health care workers and patients with liver disorders and found that the overall seroprevalence was $58.6 \%$ which is almost twice of that observed in the present study (28.9\%). ${ }^{9}$ Chakravarthi A et al, found a seroprevalence of $60.6 \%$ among patients with liver disorder which is consistant to that reported in the present study $(66.7 \%){ }^{1}$ Dharmadhikari CA et al, screened 5606 blood samples (4900 of voluntary blood donors and 706 of patients with liver disorders) and observed that seropositivity was $0.8 \%$ among voluntary blood donors and $20 \%$ among patients with liver disorders. ${ }^{3}$ Thakur et al, reported a seropositivity of $8 \%$ among health care workers and $3.26 \%$ among voluntary blood donors. ${ }^{10}$

Thus, it should be made a stringent practice that all patients with liver disorders be screened for $\mathrm{HBsAg}$ attending the hospital for control of HBV infection, as we saw that most of the patients with liver disorders were found positive. Vaccinations with recombinant DNA vaccine to prevent HBV infection should be advised and brought into practice for all medical and paramedical staff including all departments of the hospital. Effective awareness should be spread among the people with high risk behaviour to follow safe sex methods in order to acquire protection not only against HBV but also from HIV.

Attention should be directed more among younger age group like 21-40 years, as well as males for health education and screening, as these two groups are found to be at higher risk in the present study. We may conclude that mostly the patients with liver disorders especially chronic hepatitis were found to be seropositive. Being a doctor was an important risk factor for acquiring hepatitis $\mathrm{B}$ infection among health care workers. Hence, it is strictly recommended that all health care workers be immunized for hepatitis B.

Funding: No funding sources Conflict of interest: None declared

Ethical approval: The study was approved by the Institutional Ethics Committee of Indira Gandhi Medical College, Shimla, Himachal Pradesh, India 


\section{REFERENCES}

1. Chakarvarthi A, Verma V. Prevalence of hepatitis C and $\mathrm{B}$ viral markers in patients with chronic liver disease. Indian J Med Microbiol. 2005;23:273-74.

2. Blumberg BS, Mazzur S, Hertzog K, Millman I, Bloom J, Damon A. Australia antigen in Solomon Islands. Hum Biol. 1974;46:239-62.

3. Dharmadhikari CA, Kulkarni RD, Kulkarni VA, Udgaonkar US, Pawar SG. Incidence of hepatitis B surface antigen in liver disorder and voluntary blood donors. J Indian Med Assoc. 1990;88(3):73-5.

4. Chisari FV, Ferrari C. Viral Hepatitis. In: Nathanson $\mathrm{N}$ et al, editors. Viral Pathogenesis. Philadelphia, Lippincott-Raven; 1997:745-778.

5. Elavia AJ, Bank DD. Hepatitis B virus infection in hospital personnel. Natl Med J India. 1992;5(6):2658.

6. Gupta N, Kumar V, Kaur A. Seroprevalence of HIV, $\mathrm{HBV}, \mathrm{HCV}$ and syphilis in voluntary blood donors. Indian J Med Sci. 2004;58(6):255-57.

7. Patel Y. seroprevalence of HIV, HBV, HCV and syphilis in voluntary blood donors. Indian J Med Sci. 2004;58:306-07.

8. Vaiphei K, Pal NS, Arora SK. Comparative analysis of $\mathrm{HBV}$ and $\mathrm{HCV}$ infection in hepatocellular carcinoma and chronic liver disease. Indian J Pathol Microbiol. 2006;49(3):357-61.

9. Shivananda PG, Kumar A, Shetty SK. HBsAg in voluntary blood donors, hospital personnel and liver disorder patients. Proceeding Updates in Viral Hepatitis; 1990:157-159.

10. Thakur TS, Goyal A, Sharma V, Gupta ML. Incidence of Australia Antigen (HBsAg) in Himachal Pradesh. J Commun Dis. 1990;22(3):1737.

Cite this article as: Kaundal PK, Kaundal AP. A prospective study to assess the prevalence of hepatitis B infection in health care workers, voluntary blood donors, and patients with liver disorders at a tertiary care centre. Int $\mathrm{J}$ Basic Clin Pharmacol 2017;6:1708-12. 